\title{
The perception of persons with Anorexia Nervosa on Quality of Life: An initial investigation
}

\section{INTRODUCTION}

Anorexia Nervosa (AN) is an illness which has a major impact on several domains of an individual's life, including social inclusion, employment, physical health, personal development and relationships with friends and family. In order to gain better insight into this overpowering impact, the assessment of Quality of Life (QoL) has become a key part of research on AN in recent years. In general, a distinction can be made between studies focusing on Health-Related Quality of Life (HRQoL), in which satisfaction with life is considered in relation to physical and mental health, and studies focusing on QoL from a multidimensional perspective, based on the individual's personal perceptions, behaviors and circumstances (Schalock 2004). A large part of the existing QoL studies in the field of AN primarily focuses on HRQoL, which is being assessed using both generic and disease-specific instruments, such as the Medical Outcomes Study 36-Item Short Form (SF-36), the Health-Related Quality of Life in Eating Disorders Questionnaire (HErQoLED) and the Eating Disorders Quality of Life Questionnaire (EDQOL) (Engel et al. 2009; Jenkins et al. 2011; Mond et al. 2005; Mitchison et al. 2013). These studies however are subjected to a number of limitations. Firstly, the instruments often overlook the psychosocial aspects of QoL (Jones et al. 2008). Secondly, there is a lack of understanding regarding their sensitivity to the cultural, physical and social environment of the participants and the extent to which QoL is affected by a specific eating disorder diagnosis (Verdugo et al. 2005; Jenkins et al. 2011). Thirdly, most studies do not pay attention to the personal perspectives on QoL of AN-patients, as only a limited number of studies have made use of individualized measures that allow participants to define their own QoL domains, such as the Schedule for the Evaluation of Individual Quality of Life (SEIQOL) (de la Rie et al. 2007). Finally, standardized instruments do not take into account the recovery stage the participants find themselves in.

Keeping the above-mentioned limitations in mind, the knowledge base on the relationship between QoL and AN is already relatively large: almost all studies report that AN-patients have a poor QoL and that it remains poor, even after completing treatment and being recovered physically (Padierna et al. 2002; de la Rie et al. 2007). These findings are in line with the fact that AN is characterized by a poor prognosis and a very slow recovery process (Steinhausen 2009). As a consequence, it is challenging to provide treatment that fully meets the needs of the patient. Notwithstanding the fact that a wide variety of AN treatment models is available (e.g. Cognitive Remediation Therapy, mindfulness, behavioral therapy, Acceptance and Commitment Therapy, mirror therapy, motivational interviewing, family-based therapy), most of these models remain characterized by a lack of convincing empirical 
evidence and a high drop-out (Berg and Wonderlich 2013; Fairburn 2005; Guarda 2008). In recent years however, there has been a rapid growth of integrative multidisciplinary treatment programs in which several theoretical frameworks and methods are combined, such as the MANTRA-model (Maudsley Model of Anorexia Nervosa Treatment for Adults) that is developed at the King's College Institute of Psychiatry in London (Schmidt et al. 2014). In these programs, a shift is made from a focus on symptom relief and weight gain to increasing QoL, increasing autonomy, reducing anxiety and distress, restoring positive relations with others and increasing hope (Williams et al. 2010).

However, the current health-related approach to QoL in both daily practice and research is insufficient to map the active ingredients and outcomes of these new integrative types of treatment. As a consequence, it is necessary to apply a broad perspective on QoL. The reason for this is twofold. Firstly, a multidimensional approach to QoL has a better alignment with integrative multidisciplinary treatment programs, in which the primary focus is on improving subjective well-being rather than on merely reducing symptoms, often described as "problem" or "challenging" behavior. Taking into account both subjective and objective aspects of QoL fits better with these programs than a healthrelated approach to QoL. Secondly, in order to ensure that a therapeutic program can have a positive influence on the patient's QoL, it is important to verify what persons with AN themselves perceive to be a good QoL. In this respect, a widely used QoL framework is the one that is developed by Schalock and his colleagues (Schalock 2004; Schalock et al. 2002). This framework, originally developed within the field of intellectual disabilities, is increasingly applied in many other fields, such as mental health, special education, drug abuse and ageing (Verdugo et al. 2012). Schalock defines individual QoL as " $a$ multi-dimensional phenomenon that is composed of core domains that are influenced by personal characteristics and environmental variables" (Schalock et al. 2009). The following eight QoL domains are specified: personal development, self-determination, interpersonal relations, social inclusion, rights, emotional well-being, physical well-being and material well-being (Schalock 2004). These domains have proven to be universal and are operationalized by means of culturally sensitive indicators, i.e. perceptions, conditions and behaviors that give an idea of an individual's well-being (Schalock et al. 2009).

The framework of Schalock thus sheds light on the concept of QoL from a broad perspective, taking into account the personal experiences and subjective aspects of life satisfaction (Verdugo et al. 2012). In this respect, specifying the indicators of each QoL domain for individuals with AN has several advantages. Firstly, it would provide insight into what individuals with AN themselves deem important in order to have a good QoL. This implies that it becomes possible to understand the total impact that AN has on all domains of an individual's life (Jones et al. 2008). Secondly, operationalizing these indicators would have therapeutic implications because they form a good starting point for the 
development of individualized support strategies in clinical practice. Thirdly, specifying the indicators allows for applying a QoL-oriented logic model - consisting of input, throughput and output components - to treatment programs in the field of eating disorders. Using a logic model makes it possible to explain the connections between inputs (e.g. values, rationale, underlying assumptions of a treatment program) and outputs (e.g. improved well-being of patients) (Claes et al. 2010), moderated and influenced by throughput (e.g. support interventions and activities). In so doing, the specified indicators can facilitate outcome measurement, since these make it possible to verify how treatment influences the patient's QoL, as perceived by him- or herself. In other words, applying a logic model allows us to identify the active ingredients of a therapeutic program from a holistic and integrated perspective (Isaacs et al. 2009; Schalock et al. 2008).

To our knowledge, there is a lack of studies that focus on disclosing these perspectives in the existing AN research base. In order to address this knowledge gap, the present study aims to: (1) demonstrate the importance of applying a multidimensional approach to QoL in AN research by exploring the personal perspectives on the QoL of persons recovering from AN, (2) identify the specific indicators of the eight above-mentioned domains of the QoL model of Schalock in relation to persons with AN and (3) explore the influence of a specific AN treatment program in Belgium ('Empathie') on the perception of the QoL of its (ex-)patients in order to illustrate the use of a QoL logic model in the field of AN treatment. The central assumption of this study is that a multidimensional approach to QoL (as developed by Schalock, 2004) is universal and applicable to every individual, but that the interpretation of the indicators and the importance of the domains can vary between individuals. By using a broad perspective on QoL, this study aims to shed light on a more holistic method for treatment of eating disorders.

\section{METHODS}

\section{Setting}

This study is conducted in one treatment center, Empathie, a therapeutic center in Ghent (Belgium) that provides an ambulant treatment program for AN. The reason to focus solely on Empathie in this study is twofold. Firstly, focusing on one single center makes it possible to gain detailed insight into the relation between AN treatment and the perspective on QoL of its patients. Secondly, Empathie is a unique center in Belgium, both in the way that it considers the total impact of an eating disorder on the (quality of) life of an individual and in its integrative and multidimensional approach. This treatment program consists of three parts: individual consultations, family therapy and a group program in the day center. In all three parts, aspects from solution-focused therapy are combined with 
a systemic orientation. Characteristic to solution-focused therapy is that the patient is considered to be the expert and the therapist to be the coach. Based on the strengths of each individual patient, small achievable goals are put forward. Also, mindfulness, aspects of cognitive-behavioral therapy (i.e. redirecting automatic negative thoughts), drama therapy, voice therapy and psycho-education are important parts of the Empathie program. Empathie offers treatment to children and adolescents older than 12 and adults with AN, both the restricting and purging type. On average, patients follow treatment for approximately 12 months (De Ruysscher et al. 2015). A comprehensive description of the therapeutic program of Empathie can be found in a previous publication (De Ruysscher et al., 2015).

\section{Sample}

All participants were recruited from the therapeutic center Empathie. Participants were eligible for the study if they met the following inclusion criteria: (1) participants had completed a treatment program or were in the follow-up phase of treatment; (2) at the time of research, participants were at least 16 years old and (3) participants were considered able to participate by the therapists. A sample of 23 individuals met these criteria. After informing them about the study via a letter that was personally delivered by the therapists, 17 (ex-)patients agreed to participate. All were aged between 16 and 55 years of age $(\mu=27 ; S D=10.1)$. All participants were female, because there were no male patients in treatment at the time of research. This is in line with prevalence studies that show that AN predominantly occurs in women (Hoek 2006).

In order to collect self-reported information on the subjective well-being of the participants at the time of the study in a standardized way, we used the Anamnestic Comparative Self-Assessment (ACSA), originally developed by Jan Bernheim to measure subjective well-being in cancer patients. The strength of ACSA is that it is based on the internal standards (i.e. the experienced worst and best period in life) of the participants (Bernheim et al. 2006). The ACSA result is a figure between -5 (as bad as the worst period in your life) and +5 (as good as the best period in your life) that represents the self-reported subjective well-being of each participant. Table 1 gives an overview of the age, living situation, the therapy phase in Empathie and a personal assessment of their QoL.

$<$ Table $1>$

\section{Ethical aspects}


Ethical approval for the study was granted by the Ethics Committee of the Faculty of Psychology and Educational Sciences at Ghent University. Written informed consents were obtained from all participants and the parents of the participants aged under 18 . The names of the participants are changed in order to prevent identification and protect anonymity.

\section{Procedure and instruments}

In order to gain insight in the personal perspectives on QoL and identify the self-referenced indicators for each QoL domain, a qualitative research design with in-depth interviews was adopted. The strength of qualitative interviewing is that it facilitates the generation of rich and extensive data that are closely related to the personal experiences of the participants (Howitt 2010). The interview was composed of three sections, during which participants were asked to focus on the period from the first moment they realized they had an eating disorder up until now. In order to explore which themes the participants would mention spontaneously without applying the QoL framework of Schalock, the following question was asked in the first part of the interview: "Which elements are important for you to have a good quality of life?" In the second part, the Quality of Life model of Schalock was used as a guiding framework. Each domain was discussed in detail, in order to gain insight into the themes that were not mentioned spontaneously in the first part of the interview and to identify the specific indicators for each domain. In the third part, participants were asked the following questions: "To what extent has your treatment at Empathie affected your quality of life? Which of the domains that we have discussed earlier are affected by your treatment at Empathie?" The interviews were taperecorded and transcribed verbatim. A thematic analysis was conducted by the first author, following the guidelines of Braun and Clarke (Braun and Clarke 2006). The emerging themes were presented and discussed with the other authors at several moments during the analysis process, in order to create consistency and consensus.

\section{RESULTS}

\section{Global perception of Quality of Life}

When the participants were asked "Which elements are important to you to have a good quality of life?" five themes were mentioned spontaneously. In Table 2 these themes are listed together with the number of participants that mentioned these.

$<$ Table $2>$ 
This Table shows that interpersonal relationships is a central theme in all of the participants' perceptions. Every participant talked about the importance of having family and friends in order to have a good QoL. However, a remarkable distinction can be made. When talking about family (parents in particular), participants mainly mentioned the importance of their support and helpful conversations. Friends, on the other hand, were mainly seen as important in order to have fun and do relaxing activities. When talking about personal development, participants made a distinction between the importance of doing 'useful work' (such as studying, having a good job, learning a new language) and doing activities that stimulate their creativity (such as cooking, drawing, making jewelry, listening to music). The theme being able to relax covers aspects such as being able to fully enjoy relaxing activities without having feelings of guilt about it, having peace of mind, distract attention from thoughts of food and being able to let go of perfectionist behavior. Related to self-determination, participants talked about gaining a sense of freedom, becoming independent from their parents, being able to make one's own decisions and having the opportunity to make a new start. A final theme that was mentioned by three participants is having a healthy lifestyle, including both eating healthily and doing sports in a healthy way.

\section{Quality of Life domains (Schalock)}

In the second part of the interview, participants were asked about each QoL domain as defined by Schalock in order to gain insight into the related indicators. Table 3 gives an overview of the domains and the indicators that could be identified.

$<$ Table $3>$

\section{Personal development}

Intellectual challenge

Seven participants indicated that feeling challenged intellectually is beneficial for their QoL, e.g. in their studies, jobs, leisure time. This might be related to the fact that it is characteristic of AN-patients to demand perfectionist behavior and only 'useful work' of themselves.

"I just need an intellectual challenge. That is part of my quality of life. Also, it is one of the only things that I am better at than someone else. (...) I've always had the best grades. And in that respect, it is something that has grown into... I really enjoy it. And it has always been like that, not just since I started studying medicine. It has always been this way." (Anna) 
However, one participant indicated how difficult it is to maintain a healthy lifestyle in which being perfectionistic is not at the expense of one's own health and quality of life.

"The thing that has happened to me, is that by always wanting to perform good and wanting to have everything in perfect order, that I crossed the line and endangered my health. And at that point, I started questioning myself and my perfectionism and my environment. (...) But gradually, I've learnt that it is alright to have a little less control." (Jennifer)

Creative activities

Five participants mentioned that engaging in creative activities (e.g. jewelry making, cooking, music, dancing, fashion) contributes to their personal development and provides a welcome way to channel their perfectionism and negative thoughts.

"I like making jewelry, because it is creative and because it makes me think in a different way, and also because it is one of the few things that I can fully focus on. I find it really difficult to concentrate because I am constantly thinking about food, and that is one of the only things that makes me forget about food. When I'm making jewelry, I can think "hey, an hour has passed and I haven't thought about food"." (Anna)

\section{Self-determination}

Personal choice vs. Anorexic control

Six participants described the feeling of being able to let go of the rigid and overpowering control of their 'anorexic selves'. They indicated that their quality of life increased when they became conscious of the fact that the 'anorexic voice' in themselves is just a voice and that they are capable of making their own decisions in life.

"I like that I can distance myself from my thoughts and that I know that the voice in my head is just a voice. That I can do what I want, even if that voice tells me that I'm not allowed. That I simply can do it. (...) Before, I thought that voice was real and I just did everything what it told me. And if that voice told me that I couldn't eat, then I didn't eat. But after a while I could distance myself. That way I realized that if-for example - I ate something, the voice could scream, but that's it. That nothing bad would happen." (Isabelle)

\section{Setting boundaries}

Five participants talk about how they had often felt overpowered by other people around them when they were ill and the struggles they experienced to stand up for themselves. They stress the importance 
of being able to set boundaries towards others. Being able to express their own opinions and preferences helps them to be self-determined. In particular, setting boundaries with their parents was mentioned as an important step towards self-determination.

"Back then, I would never stand up for myself. I would never ask anything for myself. And now it is different. I dare to stand up for myself, but it depends against whom. I dare to tell my parents "no, I'm not joining you". Before, I would do anything they fancy, and now I can tell them "sorry, but this is not my cup of tea". A part of me feels guilty about that, but on the other hand I think "I can do this"." (Luca)

Being independent

Related to the above subcategory, being independent was also identified as an important aspect in the context of self-determination. This subcategory includes gaining feelings of personal control and experiencing a sense of freedom. Six participants mentioned this aspect and emphasized becoming independent of their parents in particular.

"There is one thing that I know for sure now: whatever is coming towards me, I will always be able to make my own decisions and decide myself whether I think it's ok or not. I will always find a solution that makes me happy, wherever I am. Now I am sure of that, however bad my situation is. I know now that you can always find something." (Lily)

However, participants who find themselves more at the beginning of their recovery process report that they prefer someone else, in particular their parents, to be in charge of the decisions they need to take. They are afraid that their 'anorexic side' would take over if they would be in charge themselves.

"I can't always make wise decisions yet in my head. I know that they (parents) can do it for me. In that sense... I have less freedom, but it is better that way. But I am hopeful for the future and I think I will regain more freedom." (Emma)

Interpersonal relations

Support from family

A group of six participants reported that it is crucial to feel supported by their parents and other close family members. The importance of support is mainly reported in relation to family and to a lesser extent in relation to friends.

"I've had many difficulties with my friends. That is why I am so attached to my family, because I know they will never let me down. Never. I have cheated on them for more than ten times and I've been putting many burdens upon them. Way more than upon any of my 
friends, because they are the ones who have to live with it all the time. It is them who have... Who had to go through everything together with me." (Lily)

Fun with friends

Being able to engage in relaxing activities and have fun with friends is reported as an essential aspect of a good QoL by six participants. This is mainly the case for participants who find themselves in an advanced stage of their recovery process. The relaxing activities they mentioned are often food-related (e.g. restaurants, dinners, parties). This could be a plausible explanation for the fact that participants who are not as far in their recovery process report to a lesser extent about such activities.

"I just find it really cozy to be with friends and I feel now that I can really enjoy it to talk about all sorts of topics. Even if it is about the smallest things that you experience in daily life. Every month we have a dinner with all friends from Antwerp - because I live there - and then we have girls night. We are not dancing on the table, but it is just so cozy. (...) It makes you feel warm. You can talk about something different. You don't need to think." (Ellie)

Feeling understood

Five participants talked about the fact that it is detrimental for their QoL when they feel like their friends and family do not understand what it is like to have AN and how it can affect their daily functioning. At the same time, however, they realize that it is hard to fully understand 'how AN works'.

"Someone once said to me "yeah, if you don't want to be so thin, then why don't you just eat fries every day?" And I really thought like "okay, whatever I tell them, they will never understand". On the outside, everything seems okay now, but the things that are happening in your head... Nobody sees them and nobody knows about them. And that can make me really upset sometimes, because I think "you really don't know what it is like"." (Anna)

\section{Social inclusion}

No isolation

Nine participants reported that they felt really isolated in their 'worst period', i.e. when the AN was dominating their lives. These participants now recognize how valuable it is for their QoL to break through this isolation and go out to meet people.

"I lost count of how many times I said no to my friends when they wanted to meet up. Just because I thought like "oh no, I'll have to worry about food and I would rather just stay at home, on the sofa." But actually, that was not clever of me. I think it would have made things easier if I just let go of my safe haven sooner. And just throw myself in it." (Olivia) 
However, four participants mentioned that they still enjoy moments of being alone, because they need these moments to unwind and recharge their batteries.

Helping others

Three participants reported that it has positive effects on their own QoL if they can help others and play a helpful role in the community around them.

"When I hear like "it is going wrong over there" or "those people are in trouble, they are not feeling well', then I always feel the urge to go help and listen. (...) That is a part of me, always wanting to help... And at the end of the day I think "I hope they go to bed with a slightly better feeling"." (Helen)

Limited circle of people

A group of four participants indicates that they prefer to be around a small number of people rather than big groups. One participant gives a possible explanation of this preference for smaller groups. She points out that many AN-patients are also highly sensitive persons. This implies that in certain situations, it is hard for them to process all the incoming sensations (e.g. noises, crowds, lights).

"Do you know the concept of 'highly sensitive persons'? I am highly sensitive, mainly auditory. And in big groups I can hear so many things... For me... It just sucks all the energy out of me. Actually it's just too many impressions. I hear too much and I see too much and I need time to process it all." (Helen)

Rights

Being treated well

Ten participants stressed the importance of being treated correctly. However, there might be a discrepancy between the subjective experience of the way one is being treated (from the perspective of the patient) and the insight that other people may have acted with well-intentioned reasons to help the patient recover from AN.

"During high school I found it really annoying because it felt as if my mom was the police through my friends. For example, after the exam period I went out with my friends. And I only had a soup, but I told my mom that I had eaten a sandwich. And then she heard through my friends that it wasn't true. And I found that really bad." (Caroline)

Emotional well-being

Structure 
Having a routine and a fixed day structure is reported as being very helpful to lead a qualitative life by a group of nine participants.

"I know that having structure and routine in my life really helped me. I managed to start eating well again because I started working. And therefore I needed to build some routine into my life like waking up early and eating at lunchtime. (...) And now I really need that structure in my life, because I can hang on to it whenever I have a bad period." (Ellie)

Self-image and self-esteem

Eight participants talked about having a positive self-image and the way being confident about oneself has a positive effect on the people close to them as well. At the same time, however, they stress how difficult it is to keep negative thoughts about themselves at bay all the time.

"I am convinced that an eating disorder can never go away completely. When I feel bad, I feel fat. But I will never relapse. Although, even that is hard to say... But I have enough healthy thoughts that keep me from losing weight. But when I feel bad, I tend to find myself fat. My self-image will never be really high." (Laura)

Being mild to oneself

This theme is related to the previous theme (self-image). Ten participants reported that the effects of having peace of mind and being mild to oneself on their QoL are not to be underestimated. Mildness implies that participants are able to control their perfectionist thoughts and behaviors, allow themselves to relax without feelings of guilt and are able to eat without constantly feeling anxious.

"Actually, the biggest luxury I have at the moment is that I have peace in my head. That I became milder to myself, because I've always been a perfectionist. But because of all the things I went through... I've never felt so close to myself as the last months. (...) And all the qualities that I have, I had lost them for a while but I finally found them again. And by having lost them for a while, I now realize how much they are worth." (Jennifer)

Talking about feelings

Seven participants said that talking about their feelings with others has a positive influence on their subjective well-being, both because it helps them to deal with difficult moments and because other people might get a better understanding of their behavior.

"You really need to talk about how you feel. Sometimes I think "oh no, I am complaining again". But at least people know what's up and how... Because sometimes you can be really arrogant or blunt because you're feeling bad. And people might take it personally, whilst it 
is actually your fault. I find it way better to talk. But it is not easy, because sometimes you really have to drag it out of me." (Ellie)

\section{Physical well-being}

Having energy

Eight participants stressed how valuable it is in their daily lives to have the energy to do all the things they want to do. These participants understand the importance of eating healthily and regularly. Remarkable for this theme is that it has a direct influence on almost all other themes discussed.

"The better I get, the more energy I have. And I know that it is the energy that I need to just live. And when you have energy, then you will attract people automatically, I think. And I feel that I am capable of a lot more, but sometimes I'm still out of energy for a while." (Fay)

"You can only be strong in your head when your body is strong too, I think. When I was really thin, I didn't have the strength and everything is a pain. You just don't have energy to fight it. It is a pain to simply walk. So... Yeah, I find it really important now." (Isabelle)

Self-care

A group of six participants reported that the more they are recovering, the better they can take care of themselves. This helps them to make responsible and flexible choices in their daily lives (cf. selfdetermination) and thus contributes to their QoL.

"For example, when I go on a camp and I need to decide myself how much I eat and stuff, it all goes better, because I feel like "I am responsible for myself here, so I have to make sure that I have enough". If I know that someone else... For example, at home I don't feel that urge, because I know that if I don't do it, my mom will do it." (Fay)

Having a healthy lifestyle

Six participants reported that they find it necessary to have a healthy lifestyle in order to feel good about one's own body and lead a good quality of life. This includes both doing enough sports and eating healthily. It is important to mention that all these participants also made a distinction between undertaking exercise in an 'unhealthy way' (i.e. in order to burn as many calories as possible) and in a 'healthy way' (in order to feel fit).

"When I'm doing sports now, I realize that it feels good. Before, I did things that were not realistic and I would just do it to make me feel better. I did it for completely wrong reasons, not to have fun. And now I do it to have fun so it's all good again." (Isabelle) 
"I know now that I have found my way. Because I was really struggling. Either you don't eat or you eat too much or you don't have a routine. Now I can appreciate that, because I do it in the right way. But if you would make me eat a hamburger every day, I'm sorry, but I'll never be the type to do that." (Ellie)

\section{Material well-being}

\section{Facilitator}

Material well-being is considered as an important facilitator to have a good quality of life by all seventeen participants because it has an influence on many other QoL domains, such as physical wellbeing (being able to buy healthy food), personal development (being able to afford books or entry fees to training courses), personal relationships (affording to go out for dinner with your friends), emotional well-being (being able to pay for therapy) and self-determination (being financially independent from your parents).

\footnotetext{
"Now I start finding it really annoying that I still don't earn my own money. For example, last year I worked 100 hours per week for an entire year but I didn't earn anything. And financially, that makes you really dependent. (...) So even if it is just for a coke and a sandwich, I still have to ask my parents "can I have 5 euros?" I just feel that I really want to be independent." (Caroline)
}

\section{Influence of Empathie}

In the third phase of the interview, participants were asked how their therapy at Empathie has affected their QoL. The participants reported that the therapeutic program at Empathie has positively influenced their QoL on the following four domains: self-determination, personal relationships, social inclusion and emotional well-being. Table 4 gives an overview of the specific indicators of these QoL domains and by how many participants they were mentioned.

$<$ Table 4 >

\section{Interpersonal relationships}

As was shown in the previous section, participants attach great importance to being supported by their family. However, it is often difficult for parents to understand AN and the way it affects the behavior of their child. Participants mentioned that Empathie played a crucial role in helping their parents 
understand what $\mathrm{AN}$ is and how they could deal with it, by actively engaging them in treatment and providing them with tools to recognize the anorectic system in their child. In so doing, the therapy at Empathie influences both the QoL of the patient and the family QoL. Participants reported that, since their parents gained a better understanding of AN and its underlying dynamics, arguments at home could be avoided and the relationships between themselves and their family members became closer.

\section{Emotional well-being}

The influence of the therapeutic program at Empathie on emotional well-being is threefold. Firstly, four participants reported that their therapy had positively influenced their self-image, because the therapists paid a lot of attention to the transformation of their automatic negative thoughts into positive ones. Secondly, four participants talked about how they learned to be mild to themselves during their time at Empathie. Various aspects of the treatment program are considered to be helpful in this regard: taking part in the mindfulness session, gaining insight in their own automatic negative thoughts through Cognitive-Behavioral Therapy (CBT) and the way in which the therapists confronted them with their destructive behaviors. Thirdly, five participants described how the therapists managed to create a very open and homely atmosphere and at the same time confront the patients with their own thoughts, behaviors and physical condition. As a consequence, patients are invited to talk freely about all their emotions and thoughts while they find themselves in a safe environment. The participants who took part in the group program of the day center also mentioned that it is helpful to talk to other patients who are going through the same recovery process.

\section{Self-determination}

Five participants talked about how they were convinced that the AN had total control over their thoughts and behaviors and that it was impossible for them to make their own decisions. In this context, the therapy at Empathie has helped them to realize they were not 'imprisoned' in this anorectic mindset and were capable and responsible of making their own choices.

\section{Social inclusion}

As was also mentioned above, social isolation is a major obstacle for many AN-patients. Six participants reported that in Empathie, they were encouraged to reconnect with their friends and actively engage in relaxing social activities (e.g. a hobby, a theatre membership, a course). In particular, the fact that the therapists helped them search for concrete strategies to get the most out of these activities was considered very helpful by these participants.

In summary, compared with the QoL indicators, the Empathie program has an influence on the following four domains: interpersonal relationships (support from family), emotional well-being (self- 
image, being mild to oneself, talking about feelings), self-determination (choice vs. control) and social inclusion (no isolation) (cf. Table 4).

\section{DISCUSSION}

In recent years, there has been a rapid increase in multidisciplinary programs for the treatment of AN, as a response to the high drop-out and poor evidence of existing treatment programs. These recent programs, such as Empathie, acknowledge the large impact of AN on the quality of life of an individual and its context (Jones et al. 2008). Therefore, the aim of this study was to gain insight into what persons with AN themselves deem important to have a good QoL. In so doing, a shift was made from a healthrelated perspective on QoL, that mainly focuses on objective and measurable aspects, towards a broad perspective that also takes subjective and contextual psycho-social and other aspects of QoL into account. By making use of the QoL framework of Schalock, we managed to operationalize each QoL domain into specific indicators, i.e. conditions, behaviors and perceptions that give an indication of the well-being of persons with AN (Schalock 2004). The value of adopting such a broad perspective on QoL and applying the framework of Schalock in the daily practice of AN treatment is twofold. Firstly, when treatment providers know what is important to the patients themselves to have a good QoL, a better alignment can be established between the patients' needs and the treatment goals (Claes et al. 2012). In this respect, a QoL-oriented logic model may offer a promising pathway to service providers when tailoring individualized support strategies. Secondly, these indicators could also be a useful tool to measure the outcomes of AN treatment. Existing AN outcome studies mainly focus on symptom reduction and physical recovery. As a result, many studies indicate that a high percentage of ANpatients (30\%) are not responsive to therapy and that treatment is characterized by a high drop-out (up to 42\%) (Ratnasuriya et al. 1991; Williams et al. 2010; Steinhausen 2009). However, few studies take other life areas (e.g. social inclusion, emotional well-being, self-determination) into account when determining the outcomes of AN treatment. In this respect, evaluating treatment outcomes from a broad perspective by making use of the QoL indicators, could put the somber prognosis of AN in a different light. Our findings are also characterized by a certain ambivalence however, as the ACSAscores of some of the participants who have 'finished' treatment show a low self-perceived QoL. This may reflect the potential tension between the patient's physical condition and the patient's own judgment about his/her well-being. This implies that a person who is physically recovered from AN and has a healthy BMI might still report a poor QoL, as is the case in 2 of the participants. On the other hand, a person might report a good QoL despite being underweight. This ambivalence seems inherent to both the clinical picture of AN and the use of subjective QoL measuring instruments. 
The presented study thus can be illustrative of the potential that lies in applying a broad perspective on QoL in the treatment of AN. More specifically, the participants' perspectives on the influence of their treatment at Empathie indicated that the therapy has an influence of several life domains, i.e. interpersonal relationships, emotional well-being, self-determination and social inclusion. These findings are not surprising, because they are in line with the overall treatment goals of Empathie. The primary focus is not on weight gain, but on establishing a warm therapeutic relationship, restoring a feeling of authenticity, making patients feel able to put themselves in a vulnerable position, empowering patients, restoring hope for the future, helping patients to have self-compassion, and restoring a more positive self-image (De Ruysscher et al. 2015).

Despite some particular strengths, including the fact that this is one of the first studies to focus on the own perceptions of AN-patients on their QoL and the application of a validated QoL framework (Schalock, 2004), the study has some limitations, which are important to take into account when interpreting the results. Firstly, the sample is rather small and is related to only one treatment center. Secondly, the sample is quite heterogeneous with regard to age and treatment phase, amongst other aspects. On the other hand, the sample solely consists of female participants, leaving out the perspective of (a minority of) male AN-patients. Thirdly, the perception of family members of the participants on the changes in QoL are not included. Fourthly, the study does not take into account the perspective of the professionals working at the Empathie center. Future research focusing on their perspective could triangulate the data collected from the patient's perspective. Fifthly, the interviews could have been linked more with the participants' specific life situations and experiences. This has been termed as episodic interviews by Flick (2009), which has the advantage that both episodic or 'experiential' knowledge and semantic knowledge, which is based on 'concepts and assumptions', can be uncovered (Flick 2009 p.185). More specifically, it would have been interesting to ask the participants to recall specific situations related to positive and negative Quality of Life-experiences, e.g. in relation to the ACSA (cf. the best and worst period in someone's life). Sixthly, the treatment center where the study took place might not be representative for other services. Therefore, more research is needed to corroborate the findings and to investigate the impact of different treatment types on the QoL of the patients. Also, it would be valuable to investigate the ambivalence between the physical condition of the patient and the patient's self-reported QoL, since it forms a difficult pitfall in QoL research within the field of AN.

To summarize, this study has explored the treatment of AN from a holistic perspective, by identifying the personal perspectives on QoL of persons with AN and specifying the indicators for each domain of the multidimensional QoL model of Schalock (2004). These results enabled us to apply a QoL-oriented logic model to a specific integrative treatment program, i.e. Empathie, in order to evaluate its impact 
on the perceived QoL of its patients. Therefore, we hope this study could stimulate other and future treatment programs in the field of eating disorders to apply a QoL-oriented framework in their daily practice and treatment evaluation.

\section{ACKNOWLEDGMENTS AND DECLARATION OF CONFLICT OF INTEREST}

This article is based on a study that was financed by Empathie. The researchers (CD, CC \& SV) declare no conflict of interest. The fourth author (PA) is connected to Empathie as she is the Director of the program. She has been involved in the study design, the interpretation of the findings based on the data that were first made anonymous and the drafting of the article. The data analysis has been carried out independently by the researchers. 


\section{REFERENCES}

Berg, K., \& Wonderlich, S. (2013). Emerging Psychological Treatments in the Field of Eating Disorders. Current Psychiatry Reports, 15(11), 1-9, doi:10.1007/s11920-013-0407-y.

Bernheim, J. L., Theuns, P., Mazaheri, M., Hofmans, J., Fliege, H., \& Rose, M. (2006). The Potential of Anamnestic Comparative Self-Assessment (ACSA) to Reduce Bias in the Measurement of Subjective Well-Being. [Article]. Journal of Happiness Studies, 7(2), 227-250, doi:10.1007/s10902-005-4755-0.

Braun, V., \& Clarke, V. (2006). Using thematic analysis in psychology. Qualitative research in psychology, 3(2), 77-101, doi:10.1191/1478088706qp063oa.

Claes, C., Van Hove, G., Vandevelde, S., van Loon, J., \& Schalock, R. (2012). The influence of supports strategies, environmental factors, and client characteristics on quality of life-related personal outcomes. Research in Developmental Disabilities, 33(1), 96-103, doi:http://dx.doi.org/10.1016/j.ridd.2011.08.024.

Claes, C., Van Hove, G., Vandevelde, S., van Loon, J., \& Schalock, R. L. (2010). Person-centered planning: Analysis of research and effectiveness. Intellectual and developmental disabilities, 48(6), 432453.

de la Rie, S., Noordenbos, G., Donker, M., \& van Furth, E. (2007). The patient's view on quality of life and eating disorders. [Article]. International Journal of Eating Disorders, 40(1), 13-20, doi:10.1002/eat.20338.

De Ruysscher, C., Annicq, P., Vandevelde, S., \& Claes, C. (2015). Anorexia Nervosa: een integratief behandelmodel. TIJDSCHRIFT VOOR PSYCHOTHERAPIE.

Engel, S., Adair, C., Hayas, C., \& Abraham, S. (2009). Health-related quality of life and eating disorders: A review and update. Int J Eat Disord, 42(2), 179 - 187.

Fairburn, C. G. (2005). Evidence-based treatment of anorexia nervosa. International Journal of Eating Disorders, 37(S1), S26-S30, doi:10.1002/eat.20112.

Flick, U. (2009). An Introduction to Qualitative Research. London: Sage.

Guarda, A. S. (2008). Treatment of anorexia nervosa: Insights and obstacles. Physiology \& Behavior, 94(1), 113-120, doi:http://dx.doi.org/10.1016/j.physbeh.2007.11.020.

Hoek, H. W. (2006). Incidence, prevalence and mortality of anorexia nervosa and other eating disorders. Current opinion in psychiatry, 19(4), 389-394.

Howitt, D. (2010). Introduction to qualitative methods in psychology: Prentice Hall New Jersey NJ.

Isaacs, B., Clark, C., Correia, S., \& Flannery, J. (2009). Utility of logic models to plan quality of life outcome evaluations. Journal of Policy and Practice in Intellectual Disabilities, 6(1), 52-61.

Jenkins, P., Hoste, R., Meyer, C., \& Blissett, J. (2011). Eating disorders and quality of life: a review of the literature. Clin Psychol Rev, 31, 113 - 121.

Jones, A., Evans, M., Bamford, B., \& Ford, H. (2008). Exploring quality of life for eating-disordered patients. [Article]. European Eating Disorders Review, 16(4), 276-286, doi:10.1002/erv.852.

Mitchison, D., Hay, P., Engel, S., Crosby, R., Grange, D., Lacey, H., et al. (2013). Assessment of quality of life in people with severe and enduring anorexia nervosa: a comparison of generic and specific instruments. BMC Psychiatry, 13(1), 284.

Mond, J., Hay, P., Rodgers, B., Owen, C., \& Beumont, P. (2005). Assessing quality of life in eating disorder patients. Quality of Life Research, 14, 171 - 178.

Padierna, A., Quintana, J., Arostegui, I., Gonzalez, N., \& Horcajo, M. (2002). Changes in health related quality of life among patients treated for eating disorders. Quality of Life Research, 11, 545 552.

Ratnasuriya, R. H., Eisler, I., Szmukler, G. I., \& Russell, G. F. (1991). Anorexia nervosa: outcome and prognostic factors after 20 years (Vol. 158, Vol. 4).

Schalock, R. L. (2004). The concept of quality of life: what we know and do not know. Journal of Intellectual Disability Research, 48(3), 203-216.

Schalock, R. L., Bonham, G. S., \& Verdugo, M. A. (2008). The conceptualization and measurement of quality of life: Implications for program planning and evaluation in the field of intellectual 
disabilities. Evaluation and Program Planning, 31(2), 181-190, doi:http://dx.doi.org/10.1016/j.evalprogplan.2008.02.001.

Schalock, R. L., Brown, I., Brown, R., Cummins, R. A., Felce, D., Matikka, L., et al. (2002). Conceptualization, Measurement, and Application of Quality of Life for Persons With Intellectual Disabilities: Report of an International Panel of Experts. Mental Retardation, 40(6), 457-470, doi:10.1352/0047-6765(2002)040<0457:CMAAOQ>2.0.CO;2.

Schalock, R. L., Keith, K. D., Verdugo, M. A., \& Gomez, L. E. (2009). Quality of life model development and use in the field of intellectual disability. In R. Kober (Ed.), Enhancing the quality of life of people with intellectual disability: From theory to practice. New York: Singer.

Schmidt, U., Wade, T. D., \& Treasure, J. (2014). The Maudsley Model of Anorexia Nervosa Treatment for Adults (MANTRA): Development, Key Features, and Preliminary Evidence. Journal of Cognitive Psychotherapy: An International Quarterly, 28(1), doi:10.1891/0889-8391.28.1.1.

Steinhausen, H. C. (2009). Outcome of Eating Disorders. Child and Adolescent Psychiatric Clinics of North America, 18(1), 225-242, doi:http://dx.doi.org/10.1016/i.chc.2008.07.013.

Verdugo, M. A., Navas, P., Gómez, L. E., \& Schalock, R. L. (2012). The concept of quality of life and its role in enhancing human rights in the field of intellectual disability. Journal of Intellectual Disability Research, 56(11), 1036-1045, doi:10.1111/j.1365-2788.2012.01585.x.

Verdugo, M. A., Schalock, R. L., Keith, K. D., \& Stancliffe, R. J. (2005). Quality of life and its measurement: important principles and guidelines. [Article]. Journal of Intellectual Disability Research, 49(10), 707-717, doi:10.1111/j.1365-2788.2005.00739.x.

Williams, K., Dobney, T., \& Geller, J. (2010). Setting the eating disorder aside: An alternative model of care. Eur Eat Disord Rev, 18(2), 90 - 96. 


\section{The perception of persons with Anorexia Nervosa on Quality of Life: An initial investigation}

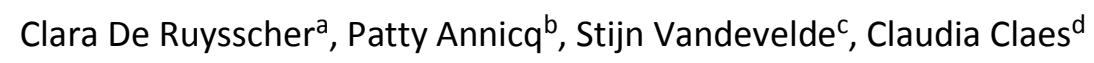

(2015)

Corresponding author: Clara De Ruysscher

a University College Ghent, Faculty of Education, Health and Social Work, Valentin Vaerwyckweg 1, 9000 Ghent, Belgium. Clara.deruysscher@hogent.be

b Vzw Empathie, Kortrijksesteenweg 686, 9000 Ghent, Belgium. Pat@annicq.com

${ }^{\mathrm{c}}$ Ghent University, Faculty of Psychology and Educational Sciences, Department of Special Education, Henri Dunantlaan 2, 9000 Ghent, Belgium. Stijn.vandevelde@ugent.be

${ }^{d}$ University College Ghent, Faculty of Education, Health and Social Work, Valentin Vaerwyckweg 1, 9000 Ghent, Belgium. Claudia.claes@hogent.be 
The perception of persons with Anorexia Nervosa on Quality of Life: An initial investigation

Table 1: Participants characteristics

\begin{tabular}{|c|c|c|c|c|}
\hline Name & $\begin{array}{c}\text { Age } \\
\text { group }\end{array}$ & Living situation & $\begin{array}{c}\text { QoL } \\
\text { (ACSA) }\end{array}$ & $\begin{array}{c}\text { Therapy } \\
\text { phase at } \\
\text { Empathie }\end{array}$ \\
\hline Laura & {$[21-25]$} & Lives with partner & 1 & Finished \\
\hline Sandra & {$[26-30]$} & Lives with partner & 4 & Finished \\
\hline Emma & {$[21-25]$} & Lives with parents & 2 & Active \\
\hline Kelly & {$[36-40]$} & Lives with parents & 5 & Active \\
\hline Anna & {$[21-25]$} & Lives at student housing & 3 & Finished \\
\hline Luca & {$[36-40]$} & Lives alone & 3 & Finished \\
\hline Lily & {$[16-20]$} & Lives with parents & -3 & Finished \\
\hline Isabelle & {$[16-20]$} & Lives with parents & 4 & Follow-up \\
\hline Caroline & {$[21-25]$} & Lives at student housing & 3 & Finished \\
\hline Ellie & {$[26-30]$} & Lives with partner & -2 & Follow-up \\
\hline Olivia & {$[16-20]$} & Lives with parents & 1 & Finished \\
\hline Eve & {$[16-20]$} & Lives with parents & 4 & Finished \\
\hline Fay & {$[16-20]$} & Lives with parents & -1 & Follow-up \\
\hline Kathy & {$[51-55]$} & Lives alone & $-2 / 3$ & Finished \\
\hline Jennifer & {$[21-25]$} & Lives with parents & 5 & Finished \\
\hline Jenny & {$[31-35]$} & Lives with parents & 4 & Finished \\
\hline Helen & {$[36-40]$} & Lives with parents & 2.5 & Finished \\
\hline
\end{tabular}

Table 2: Global perception of QoL

\begin{tabular}{|l|c|}
\hline \multicolumn{1}{|c|}{ Domain } & $\begin{array}{c}\text { Participants } \\
\text { (total: } 17 \text { ) }\end{array}$ \\
\hline Interpersonal relationships & 17 \\
\hline Personal development & 9 \\
\hline Being able to relax & 7 \\
\hline Self-determination & 5 \\
\hline Having a healthy lifestyle & 3 \\
\hline
\end{tabular}


Table 3: Domains and indicators of QoL (Schalock)

\begin{tabular}{|c|c|c|}
\hline & Domain & Indicators \\
\hline \multirow{2}{*}{ 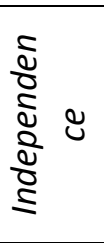 } & Personal development & $\begin{array}{l}\text { Intellectual challenge } \\
\text { Creative activities }\end{array}$ \\
\hline & Self-determination & $\begin{array}{l}\text { Choice vs. control } \\
\text { Setting boundaries } \\
\text { Being independent }\end{array}$ \\
\hline \multirow{3}{*}{ 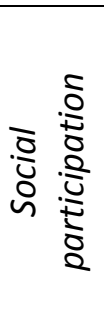 } & Interpersonal relationships & $\begin{array}{l}\text { Support from family } \\
\text { Fun with friends } \\
\text { Feeling understood }\end{array}$ \\
\hline & Social inclusion & $\begin{array}{l}\text { No isolation } \\
\text { Helping others } \\
\text { Limited circle of people }\end{array}$ \\
\hline & Rights & Being treated well \\
\hline \multirow{3}{*}{$\begin{array}{l}\frac{9}{2} \\
\frac{1}{2} \\
\frac{1}{2}\end{array}$} & Emotional well-being & $\begin{array}{l}\text { Structure } \\
\text { Self-image and self-esteem } \\
\text { Being mild to oneself } \\
\text { Talking about feelings }\end{array}$ \\
\hline & Physical well-being & $\begin{array}{l}\text { Having energy } \\
\text { Self-care } \\
\text { Having a healthy lifestyle }\end{array}$ \\
\hline & Material well-being & Facilitator \\
\hline
\end{tabular}

Table 4: Influence of treatment at Empathie

\begin{tabular}{|l|l|c|}
\hline \multicolumn{1}{|c|}{ Domain } & \multicolumn{1}{|c|}{ Indicators } & $\begin{array}{c}\text { Participants } \\
\text { (total: 17) }\end{array}$ \\
\hline Interpersonal relationships & Support from family & 8 \\
\hline Emotional well-being & $\begin{array}{l}\text { Self-image } \\
\text { Being mild to oneself } \\
\text { Talking about feelings }\end{array}$ & 9 \\
\hline Self-determination & Choice vs. Control & 5 \\
\hline Social inclusion & No isolation & 6 \\
\hline
\end{tabular}

